\title{
Latarjet Procedure: Where to Fix the Coracoid Block?
}

\section{Khelil Khaled*, Rafrafi Abderrazek, Saadi Saber, Znagui Talel and Nouisri Lotfi}

Orthopaedic Surgery Service, Main Military Hospital, Tunisia

*Corresponding Author: Khelil Khaled, Orthopaedic Surgery Service, Main

Military Hospital, Tunisia.

\author{
Received: March 09, 2020 \\ Published: April 01, 2020 \\ (C) All rights are reserved by Khelil Khaled., \\ et al.
}

\begin{abstract}
Anterior instability of the shoulder following traumatic dislocation in young adults is a common complication. The Latarjet procedure is the most used technique to treat this instability. This technique consists in making a coracoid block at the anterior edge of the glenoid to avoid anterior dislocation of the humeral head. We studied the clinical results depending on the position of the bone block in postoperative radiographs. Our study included 70 patients. The average age was 25 and a half. The sex ratio was 9 , the objective evaluation by the Duplay score was $86.6 / 100$ points. The patient satisfaction rate was $89 \%$ and the main complication was glenohumeral osteoarthritis, affecting $20 \%$ of patients. The radiological study shows that a too medial or a proximal block is accompanied by a lower stability score and lower overall Duplay. Furthermore, it leads to a significant increase in the rate of glenohumeral osteoarthritis.

Keywords: Shoulder; Dislocation; Larajet; Instability
\end{abstract}

\section{Introduction}

Anterior shoulder instability is one of the most important complications of antero-internal dislocation of the shoulder in young and active people. Among the surgical methods to treat this complication, the procedure of Latarjet [1] which constitutes the most widespread technique considering its effectiveness and its lower rate of recurrence. This procedure involves performing a coracoid block at the anterior edge of the glenoid to avoid anterior dislocation of the humeral head. Thus, the position of the block constitutes a key element of this technique.

\section{Aim of the Study}

The aim of our study is to analyze the relationship between the position of the coracoid block studied on standard post-operative radiographs and the quality of the functional results.

\section{Methods}

This is a retrospective descriptive study of patients who were hospitalized for anterior chronic instability of the shoulder treated by the Latarjet procedure in the orthopedic-trauma department of the military hospital of Tunis, over a period of 10 years between 2004 and 2014. We included in this study the patients with recurrent anterior internal dislocations of the shoulder, treated only using the Latarjet procedure. The average follow-up was 6.5 years. Other types of shoulder instability and instabilities treated by other procedures, as well as cases with a follow-up of less than a year, were not included. We also excluded all patients whose medical records were unusable and patients who were unreachable or who refused to respond to the summons. 70 files met the above criteria.
We used the delto-pectoral approach. The attitude of the operators towards the subscapularis muscle was a simple dissection in all cases. The osteochondral fragments were resected. The coracoid block was positioned in a standing position in 65 cases and in a lying position in 5 cases. The bone block was fixed either with a single AO 4.5 cortical screw in 67 cases or by two 3.5 cortical screws in 3 cases. All patients received post-operative analgesic treatment with a level 1 analgesic and an initial immobilization then a progressive rehabilitation.

The clinical evaluation was carried out objectively according to the Walch-Duplay score [1] and subjectively by questions: are you very satisfied, satisfied, disappointed, dissatisfied?

The radiological results were analyzed on 3 front views (in neutral, external and internal rotation) and a profile view of Bernageau [2]. On these radios we studied: the position of the coracoid compared to the line of condensation corresponding to the anterior edge of the glenoid. We also sought, the existence or not of a fracture, lysis, non-union of the block and the existence or not of a glenohumeral arthritis classified according to the classification of Samilson and Prieto [3].

We used the SPSS software for our statistical study. For the descriptive study we calculated simple frequencies and relative frequencies (percentage) for qualitative variables and means and standard deviations for quantitative variables. For the analytical study, the comparison of two qualitative variables was made by the Pearson chi-square test and if this test was not valid, we used 
the bilateral Fischer exact test. The comparison between a binary qualitative variable and a quantitative variable were made with the Student's t test. The level of significance $\mathrm{p}$ was set at $5 \%$.

\section{Results}

The average age at the time of surgery was 25.5 years (18 - 41 years). Our study included 63 men and 7 women. Surgery involved the dominant side in $63 \%$ of the cases. 7 patients were competitive athletes.

The clinical results according to the Duplay score is presented in table 1.

\begin{tabular}{|c|c|c|c|c|}
\hline \multicolumn{2}{|c|}{ Parameters } & Number & Percentage & Average score \\
\hline \multirow[t]{4}{*}{ A } & 0 points & 2 & $3 \%$ & \multirow[t]{4}{*}{21,15 points } \\
\hline & +10 points & 7 & $10 \%$ & \\
\hline & +15 points & 11 & $16 \%$ & \\
\hline & +25 points & 50 & $71 \%$ & \\
\hline \multirow[t]{4}{*}{ B } & -25 points & 1 & $1 \%$ & \multirow[t]{4}{*}{22,5 points } \\
\hline & 0 points & 2 & $3 \%$ & \\
\hline & +15 points & 12 & $17 \%$ & \\
\hline & +25 points & 55 & $79 \%$ & \\
\hline \multirow[t]{3}{*}{$\mathrm{C}$} & 0 points & 8 & $11 \%$ & \multirow[t]{3}{*}{19,35 points } \\
\hline & +15 points & 20 & $29 \%$ & \\
\hline & +25 points & 42 & $60 \%$ & \\
\hline \multirow[t]{4}{*}{$\mathrm{D}$} & 0 points & 1 & $1 \%$ & \multirow[t]{4}{*}{23,6 points } \\
\hline & +5 points & 6 & $9 \%$ & \\
\hline & +15 points & 24 & $34 \%$ & \\
\hline & +25 points & 39 & $56 \%$ & \\
\hline \multicolumn{2}{|r|}{$A+B+C+D$} & & & 86,6 points \\
\hline
\end{tabular}

Table 1: Clinical results according to the Duplay score and its four parameters.

A: Everyday Activities; B: Stability; C: Pain;

D: Overall Mobility; A B C D: Overall Duplay Score.

For the subjective evaluation: 62 patients (89\%) declared that they were satisfied, 5 patients $(7 \%)$ were disappointed and 3 patients (4\%) were dissatisfied.

The radiological analysis shows a block in the sub-equatorial position in 68 cases (97\%). Compared to the anterior edge of the glenoid, the block was in a flush position in 56 cases $(80 \%)$, overflowing intra articular in 12 cases (17\%), and too medial in 2 cases (3\%).

At an average follow-up of 6.5 years, we had 10 cases of lysis, only one case of non-union and no case of fractures of the block. The main complication was glenohumeral osteoarthritis. Eleven patients $(16 \%)$ developed post-operative glenohumeral arthritis. Among these patients, there was 9 cases (12.85\%) of stage 1 and 2 cases $(2.85 \%)$ of stage 2 of the Samilson classification.

The analytical study of the association between the position of the coracoid block and the mean values of the scores for stability, pain and the overall Duplay score is presented in table 2. The asso- ciation between the position of the coracoid and the post-operative osteoarthritis rate is also presented in table 2.

\begin{tabular}{|c|c|c|c|c|}
\hline & & $\begin{array}{c}\text { Flush sub } \\
\text { equatorial } \\
\text { block }\end{array}$ & Others & p-value \\
\hline \multirow[t]{5}{*}{ Stability } & -25 points & 0 & 1 & \multirow{5}{*}{$\begin{array}{c}< \\
0.0001\end{array}$} \\
\hline & 0 points & 0 & 2 & \\
\hline & +15 points & 9 & 3 & \\
\hline & +25 points & 47 & 8 & \\
\hline & Average score & 23,39 & 15,71 & \\
\hline \multirow[t]{4}{*}{ Pain } & 0 points & 2 & 6 & \multirow[t]{4}{*}{0.004} \\
\hline & +15 points & 15 & 5 & \\
\hline & +25 points & 39 & 3 & \\
\hline & Average score & 21,51 & 11,47 & \\
\hline \multicolumn{2}{|c|}{ Duplay Score (average score) } & 89,19 & 76,29 & 0.0001 \\
\hline \multirow{3}{*}{$\begin{array}{l}\text { Postoperative } \\
\text { osteoarthritis }\end{array}$} & Stade 1 & 2 & 7 & \multirow[t]{3}{*}{0.001} \\
\hline & Stade 2 & 0 & 2 & \\
\hline & $\%$ & $3 \%$ & $64 \%$ & \\
\hline
\end{tabular}

Table 2: Study of the statistical associations between the position of the coracoid block and the average score for stability, pain, overall Duplay score and the risk of postoperative osteoarthritis.

\section{Discussions}

Our descriptive study confirms the effectiveness of the Latarjet technique in the treatment of anterior shoulder instability by the high value of the overall Duplay score and by the high rate of patients satisfied with the operation. However, the main complication of this technique is glenohumeral osteoarthritis.

Our analytical study shows that the group of patients who had a coracoid block in a supra-equatorial position, overflowing intraarticular or too medial compared to the joint space expressed more feelings of instability and persistent pain during the day. In addition, the quality of the functional results evaluated by the Duplay score was reduced with statistically significant associations.

With an average follow-up of 6.5 years, we also observed a more significant post-operative osteoarthritis rate in this group of patients.

Although our study had some biases. Essentially, a selection bias relating to the retrospective nature of the study and a relatively short average decline of 6.5 years, compared to the other series. Our study is distinguished by the homogeneous nature of the population; the majority of patients is fairly young soldiers with a good physical condition. In addition, our strict exclusion criteria eliminated all unusable files.

Like our series, most of the series that have studied anterior shoulder instability have reported a young male population $[4,5]$. Older people have a loss of capsulo-ligament elasticity and a decrease in bone density, and therefore they tend to have more humerus fractures than dislocations. 
During the intervention, our attitude towards the subscapularis muscle was to make a horizontal approach at the junction $2 / 3$ upper 1/3 lower. This technique was preferred over L-tenotomy because the latter has a weakening effect on the subscapularis [6]. However, the horizontal approach makes the intervention difficult due to the reduced exposure of the glenohumeral joint.

The block has been used in standing position in most cases and in some cases lying down. A comparison of series using the block in a standing position like Doursounian [7] and Boileau [8] or lying like Hovelius [9] or Lafosse [10] did not show any difference in terms of clinical results. The fixation of the block was carried out by 4.5 screws in the majority of cases and in some cases by 3.5 screws but this has no significant influence on the clinical results as shown by the biomechanical studies of Willemot., et al [11].

During episodes of dislocation, soft tissue lesions occur. These lesions can reach the capsulo-labral and bony elements, essentially the Malgaigne notch at the humeral head and a flow or fracture of the anterior rim of the glenoid, especially the lower part, given the antero-inferior type of dislocations. Thus, the block must be in the sub-equatorial and flush position to allow the articular surface of the glenoid to be increased. For Goutallier [12] this enlargement of the glenoid makes it possible to move the Malgaigne notch away from the anterior edge of the glenoid, thus avoiding recurrences of luxation by cam effect. As a result, a supratorial position of the block $[13,14]$ or an overly medial coracoid's position are the cause of recurrent postoperative instability [15], while an overflowing block leads to a humeal's head-coracoid conflict [16]. These two positions are a source of pain $[13,16]$. This was similar to our results which objectified a decrease in the mean score for stability, pain and overall Duplay score in the group of patients with a supratorial or non-flush block.

This group reached $20 \%$ in our study. This may be due to the reduced exposure of the glenohumeral joint through the horizonal approach of the subscapularis muscle which makes it difficult to locate the block $[5,9]$.

Postoperative glenohumeral osteoarthritis is a relatively common complication following the intervention of Latarjet. Its rate is very variable in the literature $[4,13,16-18]$. In fact, the average follow-up differs from one study to another.

With $13 \%$ of stage 1 omarthrosis and $3 \%$ of stage 2 , we observed rates of omarthrosis which were quite lower than those of the Singer [13] or Allain series [19]. Bouju [18] with a follow-up of 13 years, found lower rates.

The low rate of osteoarthritis in our study can be explained by the low average follow-up which was 6.5 years. However, like most authors [20,21], we have found that a supra-equatorial or non-flush block is a major risk factor for the development of omarthrosis.

\section{Conclusion}

The Laterjet procedure for treating anterior shoulder instability is a technique that works well. Its main complication is long-term glenohumeral osteoarthritis. However, a block in the equatorial or non-flush positions significantly increases the feelings of shoulder instability and pain. Moreover, it increases significantly the rate of glenohumeral osteoarthritis. Some surgeons are now opting for arthroscopy, but the results are similar. A better patient selection, preoperative planning and bone block positioning ensure better results.

\section{Bibliography}

1. L Hovelius., et al. "Recurrences after initial dislocation of the shoulder. Results of a prospective study of treatment". Journal of Bone and Joint Surgery 65.3 (1983): 343-349.

2. J Bernageau., et al. "Value of the glenoid profile in recurrent luxations of the shoulder". Revue De Chirurgie Orthopedique Et Reparatrice De L'appareil Moteur 62.2 (1976): 142-147.

3. RL Samilson et V Prieto. "Dislocation arthropathy of the shoulder". Journal of Bone and Joint Surgery 65.4 (1983): 456-460.

4. D Gazielly. "Résultats des butées antérieures coracoïdiennes opérées en 1995 à propos de 89 cas". Revue de Chirurgie Orthopédique 86 (2000): 103-109.

5. X Cassagnaud., et al. "Clinical and computed tomography results of 106 Latarjet-Patte procedures at mean 7.5 year follow-up". Revue De Chirurgie Orthopedique Et Reparatrice De L'appareil Moteur 89.8 (2003): 683-692.

6. P Paladini., et al. "Long-term subscapularis strength assessment after Bristow-Latarjet procedure: isometric study". Journal of Shoulder and Elbow Surgery 21.1 (2012): 42-47.

7. L Doursounian., et al. "Bristow-Latarjet procedure with specific instrumentation: study of 34 cases". International Orthopaedics 33.4 (2009): 1031-1036.

8. P Boileau., et al. "Arthroscopic Bankart-Bristow-Latarjet procedure: the development and early results of a safe and reproducible technique". Arthroscopy: The Journal of Arthroscopic and Related Surgery 26.11 (2010): 1434-1450.

9. LK Hovelius., et al. "Long-term results with the Bankart and Bristow-Latarjet procedures: recurrent shoulder instability and arthropathy". Journal of Shoulder and Elbow Surgery 10.5 (2001): 445-452.

10. L Lafosse., et al. "Arthroscopic latarjet procedure". Orthopedic Clinics of North America 41.3 (2010): 393-405.

11. LB Willemot., et al. "Influence of screw type and length on fixation of anterior glenoid bone grafts". Shoulder and Elbow 10.1 (2018): 32-39. 
12. Goutallier D and Glorion CH. "Cahier d'enseignement de la SOFCOT n 49, Expansion scientifique française. Paris. La butée coracoïdienne dans les instabilités antéro-interne de l'épaule". Instabilités chroniques de l'épaule (1994): 41-46.

13. GC Singer., et al. "Coracoid transposition for recurrent anterior instability of the shoulder. A 20-year follow-up study". The Journal of Bone and Joint Surgery British 77.1 (1995): 73-76.

14. CM Robinson., et al. "Functional Outcome and Risk of Recurrent Instability After Primary Traumatic Anterior Shoulder Dislocation in Young Patients". Journal of Bone and Joint Surgery 88.11 (2006): 2326.

15. Sané AD., et al. "Echecs de la butée ostéoplastique de Latarjet. Étude préliminaire à propos de 24 cas". Acta Orthopaedica et Traumatologica Turcica 45 (2011): 268-284.

16. D Huguet., et al. "Instabilité antérieure de l'épaule chez le sportif: à propos de 51 cas de stabilisation par intervention de Latarjet-Patte". Acta Orthopaedica Belgica 62.4 (1996): 200-206.

17. C Levigne. "Résultats à long terme des butées antériures coraoïdiennes, à propos 52 cas au recul homogène de 12 ans". Revue De Chirurgie Orthopedique Et Reparatrice De L'appareil Moteur 86.1 (2000): 114-121.

18. Y Bouju., et al. “Stabilisation gléno-humérale par intervention de Latarjet-Patte modifiée: résultats avec un recul minimum de 10ans et intérêt sur la prévention de l'arthrose". Revue de Chirurgie Orthopédique et Traumatologique 100.4 (2014): S10-S16.

19. J Allain., et al. "Long-term results of the Latarjet procedure for the treatment of anterior instability of the shoulder". Journal of Bone and Joint Surgery 80.6 (1998): 841-852.

20. A Lädermann., et al. "Injury of the Suprascapular Nerve During Latarjet Procedure: An Anatomic Study". Arthroscopy 28.3 (2012): 316-321.

21. N Mizuno., et al. "Long-term results of the Latarjet procedure for anterior instability of the shoulder". Journal of Shoulder and Elbow Surgery 23.11 (2014): 1691-1699.

\section{Assets from publication with us}

- Prompt Acknowledgement after receiving the article

- Thorough Double blinded peer review

- Rapid Publication

- Issue of Publication Certificate

- High visibility of your Published work

Website: https://www.actascientific.com/

Submit Article: https://www.actascientific.com/submission.php Email us: editor@actascientific.com

Contact us: +919182824667 